\section{Sombras de humanidad: la proyección mítica de Jack el Destripador en From Hell de Alan Moore y Eddie Campbell}

Antonio Ballesteros González ${ }^{(1)}$

\begin{abstract}
Resumen: El presente artículo analiza la relevancia mítica del tristemente célebre Jack el Destripador tal y como su figura se ve reflejada en From Hell, la prestigiosa novela gráfica de Alan Moore y Eddie Campbell, publicada por primera vez entre 1989 y 1998 por la editorial Kitchen Sink Press en los EE.UU. Obra maestra del noveno arte, impregnada de intertextualidad y de múltiples significados, From Hell constituye, entre otras interpretaciones, una acerba denuncia de la sociedad victoriana profundamente escindida y dual que propició el surgimiento del primer asesino en serie moderno. La obra indaga en la atracción del mal y en la transformación del Destripador en fenómeno mediático, lo que contribuyó a convertirlo en un mito cuya ubicua y proteica presencia ha llegado hasta nuestros días, como prueban las numerosas recreaciones literarias, cinematográficas, televisivas y, en general, artísticas de la figura del asesino múltiple, dando lugar a tendencias en extremo populares, como el género "true crime".
\end{abstract}

Palabras clave: Alan Moore y Eddie Campbell - From Hell - Jack el Destripador - el asesino múltiple moderno - mito.

[Resúmenes en inglés y portugués en las páginas 84-85]

(1) Antonio Ballesteros González es Catedrático de Filología Inglesa en la Universidad Nacional de Educación a Distancia (UNED), España. Se doctoró en Filología Inglesa con Premio Extraordinario de Lectura de Tesis por la Universidad Complutense de Madrid (1993). Es autor de cinco libros. Ha editado, prologado, y en algunos casos traducido, textos de Shakespeare, Christopher Marlowe, John Ford, Aphra Behn, William Congreve, Henry Fielding, los poetas románticos ingleses, Mary Shelley, Robert Louis Stevenson, Oscar Wilde, Joseph Conrad y William Faulkner. También ha coeditado volúmenes colectivos sobre temas como el teatro de vanguardia, los textos populares, el cómic, y la enfermedad desde un punto de vista literario, y ha escrito más de 150 artículos y capítulos de libros dedicados a autores de lengua inglesa y a la literatura comparada. Como docente, ha impartido clases y conferencias en numerosas universidades, tanto españolas como extranjeras. [http://portal.uned.es/portal/page?_pageid=93,1124441\&_dad=portal\&_sche$\mathrm{ma}=\mathrm{PORTAL}]$ 
Se ha convertido en un lugar común en el contexto de la historia universal de la infamia señalar que Jack el Destripador fue el primer asesino en serie plenamente moderno. La alargada y cambiante sombra del criminal que acuchilló impunemente al menos a cinco prostitutas, aterrorizando a los atónitos habitantes de la empobrecida barriada de Whitechapel, en el East End londinense, en el justificadamente denominado "Otoño de Terror" de 1888, se ha extendido a lo largo y ancho de todo el siglo XX hasta llegar a nuestros días, donde la figura de Jack se ha transformado en un icono indiscutible de la cultura popular. Oculto en los resquicios del anonimato, el misterioso y truculento homicida se ha visto reflejado en una multiplicidad de obras y manifestaciones artísticas que abarcan lo ensayístico, lo literario, lo cinematográfico, el espectáculo musical, la televisión, el serial radiofónico, internet, los juegos de rol y multimedia, y, cómo no, el cómic y la novela gráfica. En este sentido, el tristemente célebre criminal se ha manifestado en las páginas de diferentes obras, destacando Las mil caras de Jack el Destripador, de los españoles José Ortiz y Antonio Segura, y Tesoros del crimen victoriano: Jack el Destripador, del estadounidense Rick Geary. El cómic citado en primer lugar es un magnífico ejemplo de coordinación estética entre dibujante y guionista. Con trazos definidos y un estilo marcadamente realista, que recrea con destacada negrura la sordidez convencionalmente asociada a la época victoriana, Ortiz da forma precisa a un guión en el que predomina la ubicuidad proteica del asesino, que se nos revela mediante distintos rostros que, al fin y al cabo, no concretan la identidad última del criminal del East End. En todo caso, la sucesión de episodios establecida por Ortiz y Segura dota a Jack el Destripador de un aura atrayente en la plenitud de su maldad, rasgo que no nos puede ser de ningún modo ajeno en una época como la nuestra, en la que el serial killer ha devenido en una suerte de héroe popular, como acontece, por poner algunos ejemplos significativos, en el caso del caníbal Hannibal Lecter —engrandecido por la interpretación de Anthony Hopkins en El silencio de los corderos, película basada en la novela epónima de Thomas Harris (1988) — o el refinado y frívolo Patrick Bateman de American Psycho (1991), soberbia e irónicamente retratado por la pluma de Brett Easton Ellis y degradado por las adaptaciones cinematográficas de la inteligente y aterradora novela del autor norteamericano. En los últimos años, la figura del asesino múltiple ha proliferado sobre todo en las series televisivas de plataformas como Netflix o HBO, dentro del género ya clásico del "true crime". Es el caso, entre otros muchos exponentes, de Dexter, Bones, Bates Motel, The Fall, True Detective, American Horror Story: Asylum, The Mentalist, Dark Angel o Luther, algunos de ellos inspirados en clásicos cinematográficos precedentes ${ }^{1}$. No cabe duda de que, en nuestra contemporaneidad, desde una perspectiva cultural, la seducción explícita de la maldad nos cautiva con recurrente y abrumadora frecuencia, amplificada por la inevitable manipulación mediática que nos rodea.

Por su parte, la exploración gráfica de Rick Geary incide en los macabros crímenes del Destripador desde una perspectiva testimonial, pues la historia está contada en forma de diario de un súbdito inglés coetáneo a los sangrientos sucesos que se siente al mismo tiempo fascinado y anonadado por el devenir de los mismos. Los personajes no hablan; sólo "escuchamos" la voz anónima del narrador, al tiempo que el dibujo va desgranando con contundencia, pero sin recrearse en lo visceral, el desarrollo de la trama desde dentro, desde una postura imprecisa que oscila entre la implicación y el alejamiento, decantándose finalmente — aunque no me atrevería a decir que de manera deliberada — por esta última 
opción, acaso lastrada por la imposibilidad ulterior de reconstruir la fragmentaria personalidad del asesino. Así, a pesar del estilo pseudocientífico que late en la obra de Geary, el lector no deja de percibir el desasosiego que le transmite la voz narrativa, contrapunteada por el voyeurismo de la imagen y el deseo de trascenderla para llegar más allá de la misma. En todo caso, y sin discutir el logro que suponen las historietas de Ortiz y Segura y Geary en la configuración del mito del Destripador desde un punto de vista gráfico, en mi opinión la cumbre del tema en este sentido es la novela gráfica a la que voy a dedicar esta exposición: From Hell, incuestionable obra maestra de los autores británicos Alan Moore y Eddie Campbell, publicada por entregas - a la manera folletinesca de los penny dreadful decimonónicos en Inglaterra- entre 1989 y 1998. En esta novela gráfica de extrema complejidad artística y psicológica, encabezada por el significativo subtítulo "Un melodrama en dieciséis partes" , la leyenda de Jack el Destripador alcanza ecos épicos y resonancias míticas pese a que, como suele suceder en los cómics ideados por Moore, la ambigua mitificación de su figura acabará por desmoronarse y venirse abajo ante nuestra mirada perpleja y desasosegada, proceso que culminará en una visión melancólica tras la lectura del Apéndice II del volumen, que constituye en sí un colofón metacrítico — no exento de elementos gráficos de carácter alegórico e irónico- del devenir de las teorías más significativas que han tratado de disipar la niebla que envuelve a la figura de Jack el Destripador. Dentro de la esfera del cómic y fuera de ella, Alan Moore es uno de los mayores indagadores actuales en la esencia eminentemente ambigua de lo heroico y lo mítico, según ha venido demostrando fehacientemente en paradigmas magníficos de su prolífica obra, como, por ejemplo, Marvelman (Miracleman en los Estados Unidos, con John Totleben; 19851989), V for Vendetta (con David Lloyd; 1988-1989), Swamp Thing (con Stephen Bissette y John Totleben, entre otros; 1984-1987), Watchmen (con Dave Gibbons; 1986-1987), Lost Girls (con Melinda Gebbie; 2006), y The League of Extraordinary Gentlemen (con Kevin O’Neill, 1999-2003). Esta última serie comparte con From Hell la fascinación obsesiva que Moore muestra por la época victoriana y, más concretamente, por las décadas finales del siglo XIX en Inglaterra. Según subraya el autor en el propio From Hell, la década de 1800, en la que se mezcla el imparable progreso tecnológico con los abusos del colonialismo y la deshumanización generada por la civilización industrial, contiene la esencia de lo que sería el siglo XX.

$\mathrm{Y}$ es que los estertores del Imperio de Victoria en Gran Bretaña constituyen un entramado de luces y sombras, un crisol de esplendores y miserias. En la novela gráfica que comento se perciben con claridad e inquietud los contrastes de una época dual y escindida, característica que, según he estudiado en otro lugar ${ }^{3}$, se manifiesta explícitamente en la literatura fantástica del periodo, de la que Alan Moore demuestra ser un conocedor privilegiado. Sin ir más lejos, en The League of Extraordinary Gentlemen el genial guionista reúne a un portentoso grupo de superhéroes que engloba a los grandes hitos literarios extraídos del citado ámbito, como Alan Quatermain (el aventurero protagonista de las novelas más recordadas de Rider Haggard), Jekyll y Hyde (la monstruosa pesadilla de Stevenson), el hermoso a la par que maléfico Dorian Gray, la vampirizada Mina Harker del Drácula de Bram Stoker, el conspicuo Capitán Nemo de las incomparables ficciones de Julio Verne, y el patético Hombre Invisible creado por H. G. Wells. Todos estos personajes coinciden en su reflejo de una naturaleza dual, producto coherente de la época que los origina y los acoge. 
La intertextualidad es una característica primordial de las obras de Alan Moore que no podía faltar en From Hell, donde el "héroe" definitivamente destronado será el mito par excellence de la decadencia victoriana, Jack el Destripador, vinculado a casi todos los grandes caracteres literarios de índole fantástica del siniestro instante histórico en el que actuó. Así, el asesino participa de los rasgos de Jekyll y Hyde (sobre todo si, como hacen Moore y Campbell en su novela gráfica, lo identifican con el doctor Sir William Gull, médico personal de la reina Victoria), aunando el alienante y deshumanizador progreso científico con la ansiedad regresiva de índole postdarwinista ${ }^{4}$, de acuerdo con la cual el germen bestial del primate que somos acecha en el interior del hombre.

El Londres dual por el que transitan Jekyll y su doble es la misma geografía en la que Dorian Gray, indudablemente influenciado por la huella del Destripador, comete sus crímenes innombrables e ignotos, y es también el marco por el que Drácula pulula evanescente en su elusiva ubicuidad como símbolo de "colonización a la inversa". El aristocrático no-muerto venido de los confines de la Europa oriental, símbolo de la alteridad absoluta y del miedo a lo diferente en una sociedad colonial que comercia con una multiplicidad de territorios exóticos, es retratado por Bram Stoker con evidentes rasgos semíticos, detalle que no puede serle ajeno a la leyenda del Destripador, pues Whitechapel era un barrio en el que proliferaban los habitantes de etnia judía y en el que existía una animadversión patente hacia dicha comunidad por parte de otros residentes en el distrito, antagonismo que alcanzó su momento álgido en el transcurso de las actuaciones del macabro asesino, lo que provocó importantes disturbios callejeros en el East End, en una de cuyas paredes, tras la horrenda mutilación a la que fue sometida Catherine Eddowes, apareció una extraña y ambigua inscripción tal vez relacionada con los judíos, aunque no existe una evidencia clara con respecto a esta cuestión ${ }^{5}$. De cualquier manera, no son escasas las teorías acerca de Jack que atribuyen los sanguinarios crímenes a un hombre perteneciente a la raza hebrea, símbolo de alteridad en Occidente ${ }^{6}$.

Así pues, el monstruo multiforme, producto del sueño de la razón, fatiga las calles de la metrópolis imperial, del epicentro del mundo, un lugar en el que se pueden perpetrar las más espantosas fechorías amparándose en el anonimato — denotado metafóricamente en la invisibilidad de Griffin, el hombre invisible de Wells, prototipo del científico loco- y, en los casos de Hyde, Dorian Gray y Drácula, en el poder omnímodo y fluctuante del dinero, cuya esencia, como Marx y Engels apuntan ya en el Manifiesto comunista (1848) es de naturaleza eminentemente vampírica.

En definitiva, From Hell — que constituye en sí una acumulación de textos diversos y heterogéneos, pues a los episodios de cómic como tal se unen las profusas e impagables notas aclaratorias de Alan Moore acerca de cuestiones puntuales relativas a los datos históricos o a factores culturales relevantes, fruto de una investigación exhaustiva por su parte- se nutre de todo el marco implícito de relaciones intertextuales in absentia que acabo de describir, pero al mismo tiempo, y de manera más patente, proyecta todo un haz de citas y referencias visuales y gráficas de índole tanto literaria (Blake, Alicia en el País de las Maravillas, Hazzlitt, Defoe, Bunyan, Milton, Wilde, Yeats, William Morris, Aleister Crowley, Guy de Maupassant, Kafka...) como artística, destacando en este sentido la pintura de Walter Sickert (directamente implicado en la trama del Destripador, de acuerdo con las teorías a las que Moore y Campbell se acogen) y la arquitectura del enigmático Nicholas 
Hawksmoor, cuyo edificio de Christ Church en Spitalfield, en el East End, cumple una función de icono simbólico recurrente en el devenir del argumento de la novela gráfica como umbrío recordatorio de la ubicua presencia del mal.

Los autores de From Hell insisten en desplegar ante la mirada del lector de manera gradual, y manteniendo una atmósfera por lo general opresiva, todo el variopinto collage compuesto por los principales personajes, usos y costumbres de la década de 1880 en el Londres victoriano. Así, figuras notorias - como Oscar Wilde, W. B. Yeats, Aleister Crowley, John Merrick (el llamado "Hombre Elefante", protagonista de la melodramática película de David Lynch), o la mismísima reina Victoria, impulsora indirecta de los crímenes en esta versión de la historia, que propugna la teoría de una conspiración regia- surgen en el transcurso de la narración, envueltos todos ellos — al igual que los actores principales de la tragedia, como las víctimas del Destripador, el inspector Abberline, el médium Robert Lees, el príncipe Eddy, el cochero Netley o Sir William Gull- en el contexto político, social, cultural y espiritual del momento, al que se hacen constantes alusiones ${ }^{7}$. De manera análoga, la obra de Moore y Campbell plasma la ingente riqueza lingüística de las clases bajas del East End —donde la lóbrega sordidez del entorno contrasta con la creatividad verbal de sus habitantes-, que confronta el registro elevado de las clases pudientes, revelando así la sima que separa a unos seres condenados a coexistir en el mismo tiempo y lugar, unidos todos ellos por una mente confusa y fragmentada, aquella que, simbólicamente, dará vida a Jack el Destripador. El cruento homicida será precisamente, en esta exégesis de la historia, el pivote o el nexo fundamental que vincula esos dos mundos paralelos cuyas trayectorias quedan jalonadas por constantes puntos de intersección.

Por su parte, la geografía de Londres, descrita de manera mítica y esotérica desde sus orígenes ancestrales en el magistral capítulo cuarto de From Hell, será también protagonista del drama con sus calles y monumentos, que ocultan al hombre no iniciado de finales del siglo XIX, como al de nuestros días, sus significados velados, sus misterios insondables. La ciudad - y Jack el Destripador, no lo olvidemos, es un asesino eminentemente urbano- es un palimpsesto (al igual que lo es la propia novela gráfica) en el que se han ido superponiendo diferentes capas semánticas que la historia ha ido acumulando, estratos que presentan diversos niveles de interpretación acerca de los cuales, en un periplo asombrosamente contado tanto desde una perspectiva gráfica como conceptual, el potencial asesino erudito y casi pedantesco irá haciendo partícipe a su futuro cómplice, el cochero Netley — ajeno a las sutilezas verbales y a la prodigiosa oratoria del que está a punto de convertirse en Jack el Destripador - de la pavorosa misión encargada por la propia reina para salvaguardar el honor familiar, mancillado por el matrimonio secreto del heredero de la Corona (el príncipe Albert Victor ${ }^{8}$, Duque de Clarence, llamado familiarmente "Eddy") con una dependienta, Annie Crook, ceremonia de la que serían testigos las prostitutas posteriormente despedazadas.

El mito de Jack se imbrica inexorablemente con el mito de la ciudad cuya fama, tristemente, contribuirá a incrementar (los "tours del Destripador" constituyen una de las principales atracciones turísticas del East End en nuestros días), un mapa urbano en el que dominaba la geometría sagrada de implicaciones arcanas y masónicas y en el que las ruedas del coche de caballos de Netley dibujan uno de los símbolos esotéricos más fascinantes y complejos: el pentagrama o pentáculo, la polisémica estrella de cinco puntas. Al- 
gunos emplazamientos de las miserables barriadas de Whitechapel y Spitalfields quedarán impregnados de sangre, asociados para siempre a los crímenes del Destripador, aspecto que los dibujos de Campbell reflejan ora con exactitud realista, ora con inquietantes y nebulosos trazos, según conviene a los acontecimientos que va desentrañando la trama. Otro aspecto de las postrimerías del siglo XIX en Inglaterra que Moore y Campbell proyectan con escalofriante precisión es el papel jugado por la prensa (especialmente el periódico Illustrated Police News) en la configuración del mito del Destripador, quien también ha devenido en el primer asesino múltiple moderno de la historia gracias al tratamiento mediático que le otorgaron una publicaciones periódicas sensacionalistas y sin escrúpulos que Campbell reproduce de manera fidedigna. Puede decirse sin riesgo de exagerar que Jack es, siquiera de manera parcial, una invención de la prensa amarilla de la época, deseosa de vender sus infames noticias a cualquier precio. La presión periodística, acompañada por el misterioso modus operandi del Destripador, contribuyó sobremanera a la proliferación de cartas enviadas a la policía, cuyos autores se hacían pasar por el cruento asesino. Jack —al que la primera misiva que se recibió le otorgó su infausto nombre- se convirtió en una creación del inconsciente colectivo en el que personas de un amplio espectro étnico y social vertieron sus anhelos y fantasías más ocultas y prohibidas. Hombres y ¡mujeres? ${ }^{9}$ redactaban y enviaban a los abrumados policías las siniestras epístolas en una singular manifestación comunal, sin precedentes tan palmarios hasta aquellos instantes, de los sentimientos más abyectos que anidan en el ser humano. Jack es un asesino que se refleja en la miríada de escritos que lo representan, ya sea de manera fidedigna o espuria, y que, como sucede con el vampiro en el Drácula de Stoker, se escapa a todos ellos -incluyendo los informes policiales y las noticias de la prensa-, resistiéndose a la identificación. Una de las cartas citadas, precisamente la única de la que parecen existir evidencias de que pudo ser compuesta por el auténtico Jack el Destripador, es la que da título a la obra de Alan Moore y Eddie Campbell, puesto que la dirección que se constata en la misma reza: "Desde el infierno" (From Hell). El sobre que contenía la atroz epístola iba acompañado por un paquete en el que se halló un fragmento de riñón humano. Los periódicos sensacionalistas agotaban sus ediciones y alcanzaban las más elevadas cifras de ventas hasta la fecha. ¿Nos recuerda algo este factor en lo que concierne a nuestra propia época, sometida a la tiranía constante de un sistema que potencia la exposición del individuo a la violencia explícita, mundial y morbosamente difundida y explotada? Jack adquiere así la categoría de leyenda urbana, resistente a cualquier elucubración con respecto a su etérea personalidad, a pesar de lo mucho que se ha escrito acerca del tema. El Destripador es además, en la sublimación del paroxístico salvajismo con el que trató a sus víctimas —a algunas de las cuales, en un acto de extrema proyección simbólica, llegó a extirpar el útero, la matriz u otros órganos relacionados con la procreación-, el primer asesino sexual de la historia moderna, superando en sus métodos a sádicos precursores de tiempos pretéritos, como Erszebet Báthory, merecidamente denominada la "condesa sangrienta", que gustaba de bañarse en el líquido vital de virginales doncellas con el fin de perpetuar su juventud, o como Renwick Williams, conocido con el apelativo de "el Monstruo", quien, justo cien años antes de los crímenes de Jack, en el otoño de 1788, se dedicó a apuñalar a diversas mujeres en las nalgas (por suerte, nunca mató a ninguna), sembrando el lógico caos y el miedo en las calles de Londres. 
El caso del Destripador es sintomático desde una perspectiva sexual y, desgraciadamente, ésta sería la vertiente más reiterada de su infame herencia de maldad, patentizada en la sucesión de asesinos múltiples que han configurado la crónica negra del siglo XX y de principios del XXI. Algunos representantes de esta lista aciaga — tanto del pasado como del presente, reuniendo en un brillante tour de force artístico más allá del espacio y el tiempo una lúgubre cosecha de perversidad humana- se entremezclan en el impresionante capítulo final de From Hell, en el que William Gull, aquejado de locura y encerrado en una institución mental, afronta los últimos instantes de su convulsa existencia. Ya nos habían mostrado antes los autores la fatídica y curiosa coincidencia histórica de que Adolf Hitler naciera en 1888, el mismo año de los crímenes del Destripador (Moore \& Campbell 2001: 127). Se trata de un recordatorio siempre presente en la obra de que existe un vínculo maligno entre el feroz carnicero de Whitechapel y otros ignominiosos serial killers, como el "Acuchillador de Halifax", los "Asesinos de los Páramos" o el "Destripador de Yorkshire. La violencia sexual de Jack todavía se torna más espeluznante en el relato de Moore y Campbell por el tratamiento sutil y la profunda dimensionalidad psicológica con la que los dos artistas dotan a sus personajes principales, entre los que se encuentran las desdichadas víctimas del Destripador. En este sentido, el trabajo de los autores es magistral, y hace palidecer — como en otros muchos aspectos— a la adaptación cinematográfica de la novela gráfica por parte de los hermanos Hughes (2001), interpretada por Johnny Depp, quien no puede ocultar con su aceptable interpretación el escaso acierto de quien lo escogió para dar vida en la pantalla al inspector Abberline, suprema creación caracterológica de Moore.

El retrato de las cinco mujeres sobre las que se cierne la tragedia funesta constituye un hito en el devenir histórico de la novela gráfica. El lector no puede dejar de percibir la gratuidad y el drama del exterminio al que se ven sometidas por unas circunstancias que las superan y por un ser maligno que pretende jugar a ser Dios y que, tal y como lo presentan los autores de From Hell, establece una cruzada entre lo apolíneo y lo dionisíaco, entre el sol y la luna, entre - en definitiva - las fuerzas patriarcales y el matriarcado que encumbró la figura de la Diosa en tiempos desterrados de nuestra memoria por el uso de la fuerza bruta y la manipulación ideológica que lo masculino ha ejercido contra lo femenino. No es osado, pues, subrayar que From Hell es una obra que, entre otros muchos significados, contiene un mensaje marcadamente feminista, y no en vano está dedicada a la memoria de las cinco prostitutas masacradas, infortunadas herederas de las antiguas sacerdotisas que practicaban el hieros gamos, la ceremonia tántrica del sexo sagrado que tuvo lugar en tierras occidentales en un pasado acaso más venerador de lo femenino.

No estaba lejos el instante en el que la New Woman, pionera transgresora del feminismo, irrumpiría con fuerza en Gran Bretaña, pero ninguna de aquellas cinco mujeres, víctimas de unas condiciones sociales y sexuales aberrantes, pudieron ser testigos de dicho proceso evolutivo, y ni siquiera cabe estar seguros de que haberlo contemplado les hubiera complacido. Pero, en cualquier caso, Moore y Campbell denuncian en su novela gráfica las infamantes condiciones de vida a las que se hallaban sometidas aquellas desventuradas prostitutas, cuyo oficio era considerado en la puritana Inglaterra de la época como el producto de la ninfomanía que las dominaba y a la que no se podían sustraer a causa del determinismo patológico que, de acuerdo con las teorías médicas del momento, prefijaba 
su conducta. En el reino supuestamente gobernado por el "Ángel del Hogar" victoriano, cantado ingenuamente por el poeta Coventry Patmore, el número de mujeres que se prostituían había alcanzado cotas elevadísimas. Y es que la mujer sólo podía ser ángel o demonio, madre y esposa amantísima o puta lasciva y voluptuosa; objeto sexual en todo caso, a merced de seres monstruosos como Jack el Destripador, fuera quien fuese el que se ocultara bajo su máscara, aquella que también esconde el rostro de serial killers de la realidad y la ficción, como el Michael Mayers de Halloween o el Jason de la hiperbólica y prolífica saga de Friday the 13th.

$\mathrm{Al}$ igual que en la actuación de la mayoría de los asesinos múltiples, en los crímenes del Destripador, infausto predecesor de todos ellos, el cuerpo femenino se convierte en disjecta membra, en un objeto fragmentado y mutilado en el que se desgarran salvajemente las partes de la anatomía directamente vinculadas con la potestad creativa de la mujer. El asesino patriarcal trata de usurparle y arrebatarle aquello que él odia o no puede poseer, y los cadáveres, desprovistos de los órganos extirpados, parecen ser una proyección extrema de la noción de corps morcelé lacaniano, fantasía que posee una clara relación estructural con la identidad alienante del ego, pues consiste en el medio por el cual el individuo retiene una memoria activa de su sentimiento primario de desarreglo físico, de una desintegración que se contrapone al deseo de poseer y residir en un yo coherente, seguro y corpóreo (Bowie, 1991, pp. 26-29). El serial killer, en su histérica y alienante fiebre destructora, busca recuperar en su psicología enferma y patológica la unidad perdida a través de la desmembración de lo otro (o, mejor dicho en este caso, de "la otra").

Por su parte, la fragmentación física de las víctimas del Destripador se torna en metáfora del argumento, la estructura y la forma de From Hell, rompecabezas que el lector reconstruye arduamente para llegar a la nada en la que la mayoría de los protagonistas del drama —incluido Sir William Gull— quedan sumidos al final de la obra. Jack el Destripador es en la novela gráfica de Moore y Campbell un exponente mítico de hondo influjo existencial. Tras cometer su último homicidio, Jack-Gull, quien ha anhelado convertir el asesinato en un arte - y sentirá nostalgia de su tarea una vez que su tenebrosa misión ha terminado-, afirma con orgullo blasfemo: "Para bien o para mal, el siglo veinte... lo he hecho nacer yo" (Moore \& Campbell 2001, p. 379). Y, en efecto, en el transcurso de sus crímenes — sobre todo en la denominada "fase del aura" en la que los asesinos parecen verse envueltos durante la consumación de sus actos destructivos- el médico homicida adquiere capacidad visionaria, sometido a alucinaciones premonitorias de nuestra propia época, con la que quedará irremediablemente enlazado. Este aspecto queda enfatizado sobre todo en el capítulo décimo de From Hell, donde Gull perpetra el último y el más horrendo de sus asesinatos. Pasado, presente y futuro quedan unidos en las espantosas imágenes, desprovistas de palabras en gran parte del proceso de disección del cuerpo de la víctima, mutilado hasta alcanzar un clímax de atroz y metódico arrebato: es el preludio de la barbarie de Auschwitz y los demás campos de concentración que en los siglos XX y XXI han sido y, desdichadamente, siguen siendo.

El Apéndice II de la obra, la "Danza de los cazadores de Gull"10, cierra de manera congruente el círculo de la narración, mostrándonos un espectáculo de striptease en el Ten Bells, un pub de Whitechapel, justo cien años después de que los espantosos crímenes del Destripador tuvieran lugar. Entre el público se vislumbra al propio Alan Moore, acompa- 
ñado de otros gull catchers. La ominosa iglesia de Christ Church, cuya elevada torre, alzada por Nicholas Hawksmoor, fue silencioso y privilegiado testigo de los hechos, permanece vigilante, extendiendo su sombra oscura sobre las callejuelas de Spitalfields. Una mujer que mueve su cuerpo desnudo (jacks her body) al ritmo de la música, legataria de la herencia dejada por Polly Nicholls, Annie Chapman, Liz Stride, Kate Eddowes y Marie Kelly, somete su anatomía a la mirada masculina de deseo y lujuria. Aunque George Bernard Shaw dijera con su proverbial y mordaz ironía que Jack el Destripador había sido un "reformador social" al propiciar mediante sus ignominiosos actos que los políticos británicos de la época dirigieran su atención hacia los barrios míseros y olvidados de la metrópolis londinense, aquellos descritos de manera fidedigna por Henry Mayhew en London Labour and the London Poor (1851), nada parece haber cambiado en lo esencial en el transcurso de un siglo, ni cabe pensar que vaya a hacerlo en el decurso de la historia. Una de las circunstancias que más han contribuido al proceso de mitificación del Destripador es el hecho de que se desconozca su identidad. Ahora bien, ¿importa realmente quién fuera Jack? Su leyenda se robustece y se regenera merced a una atávica sed de mal que continúa desdichadamente vigente en nuestros días, y que no tiene visos de concluir, ni siquiera a largo plazo. En todo asesino múltiple "moderno", en la realidad o en la ficción, en el "monstruo humano", como magistralmente lo definiera Isabel Santaulària (2008), reside la semilla del sanguinario homicida de Whitechapel. Jack está entre nosotros, en el salvajismo que sistemáticamente impregna la "civilización" que hemos creado y que seguimos perpetuando, para mal nuestro y del mundo que nos circunda.

Consecuentemente, abismarse en la lectura neovictoriana de From Hell constituye un reto, profundizar en una cala recóndita de nuestra propia alma, de nuestra propia existencia. Es regresar con todas las consecuencias al recurrente corazón de las tinieblas conradiano. Moore y Campbell no nos facilitan soluciones ni nos hacen concesiones nítidas, pese a darnos a conocer casi desde el principio de su novela gráfica quién es Jack el Destripador, aspecto que, paradójicamente - y como en las buenas novelas y películas de suspenseno resulta en absoluto anticlimático ni imprescindible para captar el mensaje primordial de la trama. Los autores de esta joya del cómic nos muestran en toda su lúgubre dimensionalidad la mente de un asesino, y al final del laberíntico relato no cabe dejar de preguntarse acerca del misterio postrero que habita en los recovecos de nuestro ser, de nuestra mente y nuestro pensamiento. Porque nosotros, como Jack, somos humanos (quizás demasiado humanos, como dijera Nietzsche), y en ese reconocimiento último de la potencialidad moral de nuestra común condición reside, en una proporción indeterminada según el individuo en particular, la más deslumbrante de las grandezas y la más infame de las miserias. Verse reflejado en el espejo de Jack — que vivió en una época como la victoriana, sublimada por el símbolo especular, la dualidad y las máscaras- y participar en la cíclica reconstrucción de su mito conduce ineludiblemente al estremecimiento. 


\section{Notas}

1. Véase al respecto de los asesinos en serie en la ficción el magnífico estudio de Isabel Santaulària (2008). En lo concerniente a su tipología en general, Jesús Palacios (1998) constituye una excelente introducción.

2. El volumen completo consta de catorce capítulos más un prólogo y un epílogo, a los que se añaden las notas de Alan Moore y un curioso apéndice final al que me refiero de inmediato.

3. Véase al respecto mi estudio Narciso y el doble en la literatura fantástica victoriana (Cuenca, Ediciones de la Universidad de Castilla-La Mancha, 1998).

4. La trama de The Strange Case of Dr Jekyll and Mr Hyde le fue sugerida a Robert Louis Stevenson en el transcurso de un sueño febril, y se publicó en 1886, dos años antes de que Jack el Destripador actuara en el East End.

5. El graffiti, escrito con tiza blanca sobre una pared de ladrillo negro y debajo del cual se encontró un fragmento del delantal manchado de sangre perteneciente a la víctima, decía textualmente: The Juwes are the men that will not be be Blamed for nothing ("Los Juvíos [sic] son los hombres que no serán Culpados de nada"). Aunque el vocablo Juwes no tiene por qué hacer referencia directa a los judíos (pues la palabra inglesa que traduce este término es Jews) y podría explicarse en un contexto masónico, Sir Charles Warren, comisario jefe de la policía metropolitana londinense ordenó que fuera borrada y no quiso dejar tiempo para que se tomara una fotografía de la misma con la excusa — acaso comprensible - de que los habitantes del distrito pudieran interpretar que estaba vinculada a los judíos y, por consiguiente, haber podido producir graves altercados callejeros. Consúltense acerca de esta cuestión las notas del propio Alan Moore a las páginas 277 a 282 de From Hell o, para mayor información, el libro de Evans y Skinner (2003) recogido en el apartado bibliográfico.

6. Es el caso de Paul Begg en Jack the Ripper: The Uncensored Facts, citado en la bibliografía.

7. Cabe referirse en este sentido a las menciones de aspectos ocultistas, como los relacionados con la masonería, las sociedades secretas - destacando la Golden Dawn in the Outer y la Sociedad Teosófica- y el espiritismo, del que Arthur Conan Doyle, magno creador de Sherlock Holmes e investigador por su cuenta y riesgo de los crímenes del Destripador, fue uno de los principales adalides en las postrimerías del victorianismo.

8. Nadie ha conseguido hasta la fecha demostrar la implicación de este personaje en la trama de Jack el Destripador y, consecuentemente, en la supuesta conspiración monárquica en la que numerosos autores lo inculpan. Lo que sí es cierto es que el príncipe, que tenía tendencias bisexuales, se vio envuelto en diversos escándalos y episodios oscuros, sobresaliendo entre ellos el del prostíbulo homosexual de la calle Cleveland —-donde estaba situada la confitería en la que trabajaba Annie Crook-, lupanar que, al parecer, solía frecuentar y en el que fue descubierto en el transcurso de una redada policial.

9. Precisamente, la única impostora a la que se detuvo relacionada con este sórdido asunto fue una mujer llamada Maria Coroner, la sola autora de una carta firmada con el nombre de Jack el Destripador de la que se ha llegado a dilucidar con éxito su identidad. 
10. Título que encubre un intraducible juego de palabras en inglés, pues Gull, el apellido del "verdadero" Jack el Destripador en la brillante ficción urdida por Moore y Campbell, significa en la citada lengua "gaviota". A este respecto, no puede ser azarosa la utilización simbólica de la imagen de gaviotas muertas en la playa de Bournemouth tanto en el Prólogo como en el Epílogo de From Hell.

\section{Referencias bibliográficas}

Ballesteros González, Antonio. (1998). Narciso y el doble en la literatura fantástica victoriana. Cuenca: Ediciones de la Universidad de Castilla-La Mancha.

Begg, P. (1988). Jack the Ripper: The Uncensored Facts. Londres: Robson Books.

Bowie, Malcolm. (1991). Lacan. Londres: Fontana ("Modern Masters").

Ellis, B. E. (1991). American Psycho. Londres: Vintage.

Evans, S. P. y Skinner, K. (2003). Jack el Destripador: Cartas desde el infierno. Madrid: Jaguar. [Edición original en inglés: Jack the Ripper: Letters from Hell. Londres: Sutton, 2001].

Geary, R. (2003). Tesoros del crimen victoriano. Jack el Destripador. Alicante: Editorial Club Universitario. [Edición original en inglés: A Treasury of Victorian Murder: Jack the Ripper. Boston: Little Brown, 1995].

Harris, Thomas. (1988). The Silence of the Lambs. Nueva York: St. Martin's Press.

Mayhew, H. (1985). London Labour and the London Poor. Harmondsworth: Penguin.

Moore, A. y Campbell, E. (2001). From Hell. Barcelona: Planeta ("Colección Trazado"). [La obra original en inglés apareció entre 1989 y 1998, editada por la editorial Kitchen Sink Press en los EE.UU. El volumen completo en lengua inglesa fue publicado en Londres por Knockabout Comics, 2006].

Palacios, J. (1998). Psychokillers. Anatomía del asesino en serie. Madrid: Temas de Hoy.

Ortiz, J. y Segura, A. (1984). Las mil caras de Jack el Destripador. Barcelona: Toutain, "Joyas de Creepy".

Santaulària, I. (2008). El monstruo humano. Una introducción a la ficción de los asesinos en serie. Barcelona: Laertes.

\section{Apéndice bibliográfico}

El presente apartado bibliográfico, sin pretender ser exhaustivo, contiene los ejemplos más señeros de la denominada "Literatura del Destripador", es decir, los ensayos imprescindibles que tratan de dilucidar en toda su extensión tanto las teorías sobre la identidad de Jack the Ripper como los acontecimientos que tuvieron lugar en aquel otoño sangriento de 1888.

Begg, P. y Bennett, J. G. (2017). Jack the Ripper. Londres: André Deutsch. 
Begg, P., Fido, M. y Skinner, K. (1996). The Jack the Ripper A to Z. Londres: Headline (edición revisada).

Cornwell, P. (2003). Portrait of a Killer: Jack the Ripper —Case Closed. Nueva York: Time Warner.

Cullen, T. (1965). Autumn of Terror: Jack the Ripper, His Crimes and Times. Londres: The Bodley Head.

Evans, S. P. y Skinner, K. (2002). The Ultimate Jack the Ripper Sourcebook: An Illustrated Encyclopedia. Londres: Robinson.

Feldman, P. H. (1997). Jack the Ripper: The Final Chapter. Londres: Virgin.

Hainsworth, J. y Ward-Agius, C. (2020). The Escape of Jack the Ripper: The Full Truth about the Cover-up and His Flight from Justice. Londres: Amberley Publishing.

Howells, M. y Skinner, K. (1987). The Ripper Legacy. Londres: Sidgwick \& Jackson.

Johnson, D. (2017). Jack the Ripper: Truth, Lies and Conspiracy. CreateSpace Independent Publishing Platform.

Knight, S. (1976). Jack the Ripper: The Final Solution. Londres: Harrap.

Odell, R. (1965). Jack the Ripper in Fact and Fiction. Londres: Harrap.

Palacios, J. (2004). "Desde el infierno", en Desde el infierno. Una historia oculta del siglo XX. Madrid: Oberon, págs. 73-81.

Rubenhold, H. (2019). The Five: The Untold Lives of the Women Killed by Jack the Ripper. Londres: Doubleday.

Rumbelow, D. (1988). The Complete Jack the Ripper. Harmondsworth: Penguin (edición revisada).

Sugden, P. (2002). The Complete History of Jack the Ripper. Londres: Robinson (edición revisada).

Trow, M. J. (2019). Interpreting the Ripper Letters: Missed Clues and Reflections on Victorian Society. London: Pen and Sword True Crime.

Wilson, C. (1969). A Casebook for Murder. Londres: Leslie Frewin.

Wilson, C. y Odell, R. (1987). Jack the Ripper: Summing Up and Verdict. Nueva York: Bantam.

\begin{abstract}
This article analyses the mythical relevance of the infamous Jack the Ripper as his figure is reflected in From Hell, the prestigious graphic novel by Alan Moore and Eddie Campbell, published for the first time from 1989 to 1998 by Kitchen Sink Press in the USA. A masterpiece of the ninth art, impregnated with intertextuality and multiple meanings, From Hell constitutes, among other interpretations, an acerbic condemnation of the deeply divided and dual Victorian society that propitiated the rise of the first modern serial killer. The graphic novel delves into the attraction of evil and the transformation of the Ripper in a media phenomenon, which contributed to turn him into a myth whose ubiquitous and protean presence has reached our contemporary times. This is attested by many literary, cinematographic, TV, and, in general terms, artistic recreations of the figure of the serial killer, giving rise to extremely popular trends like the "true crime" genre.
\end{abstract}


Keywords: Alan Moore and Eddie Campbell - From Hell - Jack the Ripper - the modern serial killer - myth.

Resumo: Este artigo discute a relevância mítica do infame Jack, o Estripador, como sua figura é refletida em From Hell, a prestigiada graphic novel de Alan Moore e Eddie Campbell, publicada pela primeira vez entre 1989 e 1998 pela Kitchen Sink Press na obra-prima dos EUA da nona arte, mergulhada em intertextualidade e múltiplos significados Do Inferno está, entre outras interpretações, uma denúncia acerba de sociedade vitoriana profundamente dividida e dupla que levou ao surgimento do primeiro serial killer moderno. A obra mergulha na atração do mal e na transformação do Estripador em um fenômeno midiática, que contribuiu para transformá-lo em um mito cuja presença onipresente e proteica chegou até hoje, como evidenciado pelas numerosas recriações literárias, cinematográficas, televisivas e, em geral, recriações artísticas da figura do assassino múltiplo, dando origem a tendências extremamente populares, como o gênero "verdadeiro crime".

Palavras chave: Alan Moore y Eddie Campbell - From Hell - Jack, o Estripador - serial killer moderno - mito.

[Las traducciones de los abstracts fueron supervisadas por el autor de cada artículo] 